\title{
A systematic review and meta-analysis of catheter ablation for atrial fibrillation
}

\author{
Peng Wang ${ }^{1,2}$, Wuyang He ${ }^{1}$, Chunqiu Li ${ }^{1}$, Tingting Xiang ${ }^{1}$, Qiaoyun Yang ${ }^{1}$, Qingwei Chen ${ }^{1}$ \\ ${ }^{1}$ Department of Geriatrics, the Second Affiliated Hospital of Chongqing Medical University, Chongqing, China; ${ }^{2}$ Department of Geriatrics, Fuling \\ Central Hospital of Chongqing City, Chongqing, China \\ Contributions: (I) Conception and design: P Wang, Q Chen; (II) Administrative support: W He, C Li; (III) Provision of study materials or patients: P \\ Wang, W He, C Li, T Xiang, Q Yang; (IV) Collection and assembly of data: All authors; (V) Data analysis and interpretation: P Wang, T Xiang, Q \\ Yang, Q Chen; (VI) Manuscript writing: All authors; (VII) Final approval of manuscript: All authors. \\ Correspondence to: Qingwei Chen. 74 Linjiang Road, Yuzhong District, Chongqing, China. Email: chenqwcq@163.com.
}

\begin{abstract}
Backgrounda This study analyzes and compares the efficacy of using catheter ablation (CA) and traditional drug treatments for atrial fibrillation (AF). Through a systematic review and meta-analysis, it seeks to provide a theoretical basis for using clinical CA for patients with $\mathrm{AF}$.

Methods: We searched through articles detailing randomly controlled trials (RCTs) that assessed the surgical effect of CA on the treatment of AF. These articles were published before January 31, 2000 in various English databases, including PubMed, Embase, Medline, Ovid, Springer, and Web of Sciences. The Cochrane Handbook for Systematic Reviews of Intervention 5.0.2 was adopted for the bias risk assessment, and Review Manager 5.3 software was used for the meta-analysis of the articles.
\end{abstract}

Results: A total of 2,098 patients drawn from 13 articles were included in the study. For patients in the experimental group (Exp. group), the meta-analysis showed an increase in the effects of clinical treatment [mean deviation $(\mathrm{MD})=3.91 ; 95 \%$ confidence interval $(\mathrm{CI}), 3.15-4.85 ; \mathrm{Z}=12.36 ; \mathrm{P}<0.00001$ ], an improvement in daily life function ( $\mathrm{MD}=1.45 ; 95 \% \mathrm{CI}, 1.03-1.87 ; \mathrm{Z}=6.82 ; \mathrm{P}<0.00001$ ), a decrease in body weakness ( $M D=-2.84 ; 95 \% \mathrm{CI},-3.24$ to $-2.45 ; \mathrm{Z}=14.16 ; \mathrm{P}<0.00001)$, and an increase in quality of life score $(M D=14.15 ; 95 \% C I, 7.24-21.05 ; Z=4.01 ; P<0.0001)$. The Exp. group also experienced a reduction in postoperative pain level $(\mathrm{MD}=-2.5 ; 95 \% \mathrm{CI},-3.11$ to $-1.89 ; \mathrm{Z}=8.04 ; \mathrm{P}<0.00001)$, reoccurrence of symptomatic $\mathrm{AF}(\mathrm{OR}=0.27 ; 95 \% \mathrm{CI}, 0.11-0.67 ; \mathrm{Z}=2.82 ; \mathrm{P}=0.005)$, rehospitalization $(\mathrm{MD}=0.15 ; 95 \% \mathrm{CI}$, $0.07-0.31 ; \mathrm{Z}=5.11 ; \mathrm{P}<0.00001)$, other arrhythmia $(\mathrm{MD}=0.33 ; 95 \% \mathrm{CI}, 0.18-0.6 ; \mathrm{Z}=3.62 ; \mathrm{P}=0.0003)$, and pulmonary vein stenosis (PVS) $(\mathrm{MD}=0.32 ; 95 \% \mathrm{CI}, 0.14-0.72 ; \mathrm{Z}=2.74 ; \mathrm{P}=0.006)$. However, in contrast to patients in the control group (Ctrl group), the 'bleeding' mentioned above showed no statistical difference.

Discussion: CA has a good postoperative clinical effect on AF patients, reducing incidences of pain, adverse reactions, and rehospitalization. For this reason, CA is a suitable treatment for AF patients who do not effectively respond to drug therapy.

Keywords: Atrial fibrillation (AF); arrhythmia; catheter ablation (CA); drugs; treatment effect

Submitted Jul 29, 2021. Accepted for publication Oct 14, 2021.

doi: $10.21037 / \mathrm{apm}-21-2313$

View this article at: https://dx.doi.org/10.21037/apm-21-2313

\section{Introduction}

Atrial fibrillation (AF) is the most common persistent arrhythmia. According to statistics, incidences of AF continue to increase with age, reaching $13 \%$ of people over
75 years (1). The frequency of atrial activation in people with $\mathrm{AF}$ is $300-600$ beats $/ \mathrm{min}$. As the heartbeat frequency is often fast and irregular, sometimes increasing up to $100-160$ beats/min (which is much faster than regular people), it results in ineffective contraction functions. 
The prevalence of $\mathrm{AF}$ is also closely related to diseases such as coronary heart disease (CHD), hypertension, and heart failure. One of the main risks associated with $\mathrm{AF}$, is that when it is complicated by stroke and heart failure, it can cause death in severe cases (2-4). The basic mechanism of atrial fibrillation is related to the complex interaction between triggering foci and stroma. The trigger is responsible for initiating the arrhythmia (atrial fibrillation), and the stroma is responsible for maintaining the arrhythmia. When the myocardium is induced enough to overcome the recovery repolarization after the action potential is depolarized, trigger activity will occur, causing premature contractions (premature beats), but it can't maintain persistent arrhythmia. However, when the pulses generated by these premature beats are released at a high frequency and when they encounter myocardium with variable excitability or refractory, functional electrical block and even reentrant excitement will occur. The emergence of reentrant excitement will generate new impulses and additional reentrant excitement to help maintain arrhythmia. The goal of clinically treating AF is mainly to restore sinus rhythm, with the two main directions of treatment being drugs and catheter ablation (CA) (5). Catheter radiofrequency ablation is one of the methods to treat arrhythmia. Under the monitoring of the $\mathrm{X}$-ray angiography machine, the operation is performed by puncturing the blood vessel and inserting the electrode catheter into the heart. Firstly, it checks to determine the position of the abnormal structure causing the tachycardia, and then locally releases high-frequency currents. The high temperature is generated in the range, and through the thermal efficiency, the water in the local tissue evaporates, dries, and returns to necrosis, to achieve the purpose of treatment. However, catheter ablation also has disadvantages. For patients with hypertrophic cardiomyopathy, dilated cardiomyopathy, and heart failure, and other patients with atrial fibrillation, the effect of catheter ablation is not good, and it may increase the symptoms of discomfort and aggravate the condition. Because of these cardiomyopathy or heart failure patients, most of the atrium pressure increases, and local atrial muscle aging (fibrosis) is obvious. It is difficult for the energy of catheter ablation to form a transmural injury, and local burns are not penetrated. Instead, atrial flutter may be formed. The heartbeat of atrial flutter is faster and more difficult to control. The drug does not work well, which may make the patient's heart failure worse. According to current treatment guidelines, although drugs are the primary recommendation for treating $\mathrm{AF}$, they can result in a higher reoccurrence rate, limited efficacy, and a higher chance of adverse reactions in patients (6).

Many studies have found that CA treatment for AF can reduce the reoccurrence rate of the disease. However, CA is an invasive treatment method and can cause great harm to patients, so the success rate of CA remains low. According to relevant statistics, the occurrence and prognosis of $\mathrm{AF}$ have certain regional and ethnic differences, so it is impossible to effectively make accurate judgments on the efficacy of CA in the treatment of AF. To further confirm the efficacy of CA, this study conducted a meta-analysis of articles that used randomly controlled trials (RCTs) to analyze the clinical application of CA in the treatment of AF. Through this approach, we aim to provide a theoretical basis for evaluating the efficacy of using $\mathrm{CA}$ for AF. This study adopted the method of systematic review and metaanalysis to discuss the results, the sample size was large, the effectiveness and safety indicators were analyzed many times, and the scientific conclusion of the method was more accurate. We present the following article in accordance with the PRISMA reporting checklist (available at https:// dx.doi.org/10.21037/apm-21-2313).

\section{Methods}

\section{Inclusion and exclusion criteria of articles}

The inclusion criteria for articles were defined as follows: patients aged 18-80 without limitation on gender; patients diagnosed with AF within the past 6 months by ECG, Holter, or other examination; RCTs published in English, and in foreign English databases; CA treatment had to have been given to an experimental (Exp.) group, and conventional drug treatment to a control (Ctrl) group. The baseline data of the Exp. and Ctrl groups also had to be comparable.

The exclusion criteria were defined as follows: retrospective studies, cohort studies, case reports, and other non-RCT research; research subjects of non-AF patients or animals, children, and cells; if CA and conventional drug treatment were not used; unpublished articles or nonEnglish articles such as a thesis; research subjects with AF combined with other diseases; research subjects with incomplete data; and republished articles.

\section{Article retrieval}

A total of 6 English databases (PubMed, Embase, Medline, 
Spring, Cochrane Library, and Web of Sciences) were searched for articles that used RCTs to research AF, and all were published before January 31, 2000. The literature search terms were composed of subject words and free words, including "catheter ablation", "atrial fibrillation", "measurement", and "clinical effect". These were combined with "and" or "or".

\section{Article screening}

Article retrieval was performed by 2 researchers independently. After retrieving the articles, their titles were entered into NoteExpress 3.2 software to establish a document database and remove any duplicates. Two researchers were then invited to independently complete the screening of the articles. Firstly, they conducted a preliminary screening by reading the titles and abstracts of the articles. From this, they determined which would be relevant to the meta-analysis and deleted any articles that did not obviously meet the study's requirements. The full text was then read to determine whether it could be included according to the inclusion and exclusion criteria. If the data in the article was not clearly described, more detailed information was sought from the author. If the data in question was not available, it would be directly excluded. After the article screening, the articles that met the requirements were sorted. Any disagreement between the 2 researchers during the screening process was resolved through discussion. If a consensus could not be reached, a third researcher was asked to arbitrate.

\section{Data extraction}

For data extraction, 2 researchers extracted the data independently and then performed a cross-check. The relevant data for this study included basic information of the article (document title, first author, publication year, author information, and document source, etc.), comparable basic characteristics of patients (gender, age, research sample size, and baseline comparability, etc.), intervention measures in the Exp. group and Ctrl group, and outcome evaluation indicators (effect of clinical CA treatment, daily life function, body weakness, and rehospitalization). If there was any disagreement between the 2 researchers during data extraction, it was resolved through discussion or by a third researcher.

\section{Assessment on bias risk}

The Cochrane Handbook for Systematic Reviews of Interventions 5.1.0 was adopted to assess the bias risk of the included articles in this study. We assessed the bias risk using the following items: whether it was a random sequence (e.g., a random number table or other random method used to randomize the research subjects); if allocation concealment was implemented (e.g., if groups were created randomly to ensure the confidentiality of patients); whether patients were selected blind (e.g., if the clinical research patients knew they were being included in the study by receiving the relevant intervention and being allocated to a group); whether the outcome was assessed blind (e.g., if the researcher or the outcome assessor knew the patient's group and the interventions received); whether the data were complete or if some data were missing; whether the research had selective reporting; and whether there were other biases. In the assessment of an article's risk bias, if there was any disagreement between the 2 researchers, it was resolved through discussion or by a third researcher.

\section{Sensitivity analysis}

Sensitivity analysis was used to evaluate whether the results of the meta-analysis were stable and reliable, specifically by excluding some controversial studies, low-quality studies, or using different statistical methods/effect models to analyze the same set of data, and observe the changes in the results of the meta-analysis. If the sensitivity analysis did not substantially change the results, the results were reliable. Instead, it indicated that researcher should be very cautious in interpreting results and drawing conclusions.

\section{Statistical analysis}

STATA 12.0 software, Cochrane Handbook for Systematic Reviews of Interventions 5.1.0, and Review Manager 5.3 software were adopted to merge the statistics of the included articles, evaluate each article's individual risk of bias, and perform a meta-analysis of the combined statistics. If the unit of measurement was not uniform between different samples, it was expressed in the form of standardized mean difference (SMD). If it was found that the results of each study could be combined, a meta-analysis 
was performed. Binary variables took the relative risk (RR) and 95\% confidence interval (CI) as effective sizes, while continuous variables used SMD and 95\% CI. Forest diagrams and funnel diagrams were then drawn based on the analysis results. In meta-analysis, the article was tested for heterogeneity using the $\mathrm{I}^{2}$ test to observe whether the studies could be combined, and the $\mathrm{P}$ value was used as an index to evaluate the heterogeneity. If the result of the heterogeneity test was $\mathrm{I}^{2} \geq 50$ and $\mathrm{P}<0.05$, it suggested that the heterogeneity among the included studies was small, and the fixed effects model (FEM) could be adopted for a metaanalysis of the combined effect size. If the heterogeneity test result showed $\mathrm{I}^{2}<50$ and $\mathrm{P}>0.05$, it indicated that there was a certain heterogeneity among the included studies, so the random effects model (REM) could be applied for metaanalysis. The $U$ test was utilized to judge whether there was statistical significance between the combined effect sizes, the probability $\mathrm{P}$ value was calculated based on the $\mathrm{U}$ value. $\mathrm{P}<0.05$ indicated that the difference was statistically significant.

\section{Results}

\section{Article retrieval results}

The preliminary search obtained 1,649 references related to the subject. After reading the title, 621 references that were completely inconsistent were excluded. After reading the abstract, 849 articles that did not meet the inclusion criteria were excluded. After carefully reading the title and abstract, 149 articles that did not meet the requirements such as repeated publications or individual cases were excluded. After downloading the documents, read the full text carefully and exclude 17 documents that do not meet the requirements. Finally, a total of 13 studies were included for meta-analysis. These 13 articles (7-19) included 2,098 patients, 1,151 of which were allocated to an Exp. group, and 947 of which were allocated to a Ctrl group. The baseline data of the 2 groups were comparable (Table 1). The specific process of article retrieval is shown in Figure 1.

\section{Assessment of bias risk in included articles}

The Cochrane Handbook for Systematic Reviews of Interventions 5.0.2 was adopted to assess the bias risk of the 13 articles included, and Review Manager 5.3 software was applied to produce the bias risk chart shown in Figures 2 and 3. The risk of bias was determined by assessing the following: random sequence [all the 13 included articles (7-19) were a random grouping, resulting in 8 articles being considered as "low risk"], allocation hiding (all 13 articles did not mention allocation hiding, indicating an "unclear risk"), subject blinding (13 articles did not mention such information, indicating an "unclear risk"), blinding to outcome assessor (13 articles did not mention such information, suggesting an "unclear risk"), data completion (all 13 articles had complete data, indicating a "low risk"), selective reporting (no selective reporting was found in the 13 articles, indicating a "low risk"), and other biases (12 articles included a different number of cases in the Exp. and Ctrl groups, showing a "high risk"; and 1 article was impossible to judge, so it was an "unclear risk").

\section{Effect of clinical CA treatment}

A total of 9 articles (10,12-19) analyzed the effect of clinical CA treatment on AF patients. This included 1,694 patients (Exp. group =923, Ctrl group =771). The heterogeneity test results $\left(\mathrm{I}^{2}=32 \%, \mathrm{P}=0.16\right)$ suggested that the heterogeneity among the studies was small, so a FEM was used for analysis. The results shown in Figure 4 illustrate that the combined effect of this meta-analysis was OR $=3.91$ ( $95 \%$ CI, 3.15-4.85; $Z=12.36$; and $\mathrm{P}<0.00001$ ). The diamond in the forest diagram was located on the right side of the vertical line, suggesting that using $\mathrm{CA}$ to treat $\mathrm{AF}$ resulted in a higher clinical effect in the Exp. group than in the Ctrl group.

\section{Daily life function}

We analyzed 4 articles $(7,9,14,15)$ on the daily life function of patients. This included a total of 393 patients (Exp. group $=219$; Ctrl group =174). The heterogeneity test result $\left(\mathrm{I}^{2}=96 \%\right.$, and $\left.\mathrm{P}<0.00001\right)$ indicated that there was a certain degree of heterogeneity among the studies, so a REM was adopted. The analysis results in Figure 5 indicate that the combined effect of this meta-analysis was $\mathrm{MD}=1.45 ; 95 \%$ CI, 1.03-1.87; $\mathrm{Z}=6.82$; and $\mathrm{P}<0.00001)$. In addition, the diamond in the forest diagram was located on the right side of the vertical line, suggesting that using $\mathrm{CA}$ to treat $\mathrm{AF}$ resulted in a higher daily life function in the Exp. group.

\section{Body weakness}

We analyzed 4 articles (7,17-19) that looked at body weakness. This included 563 patients (Exp. group =304; 
Table 1 Basic data of included articles

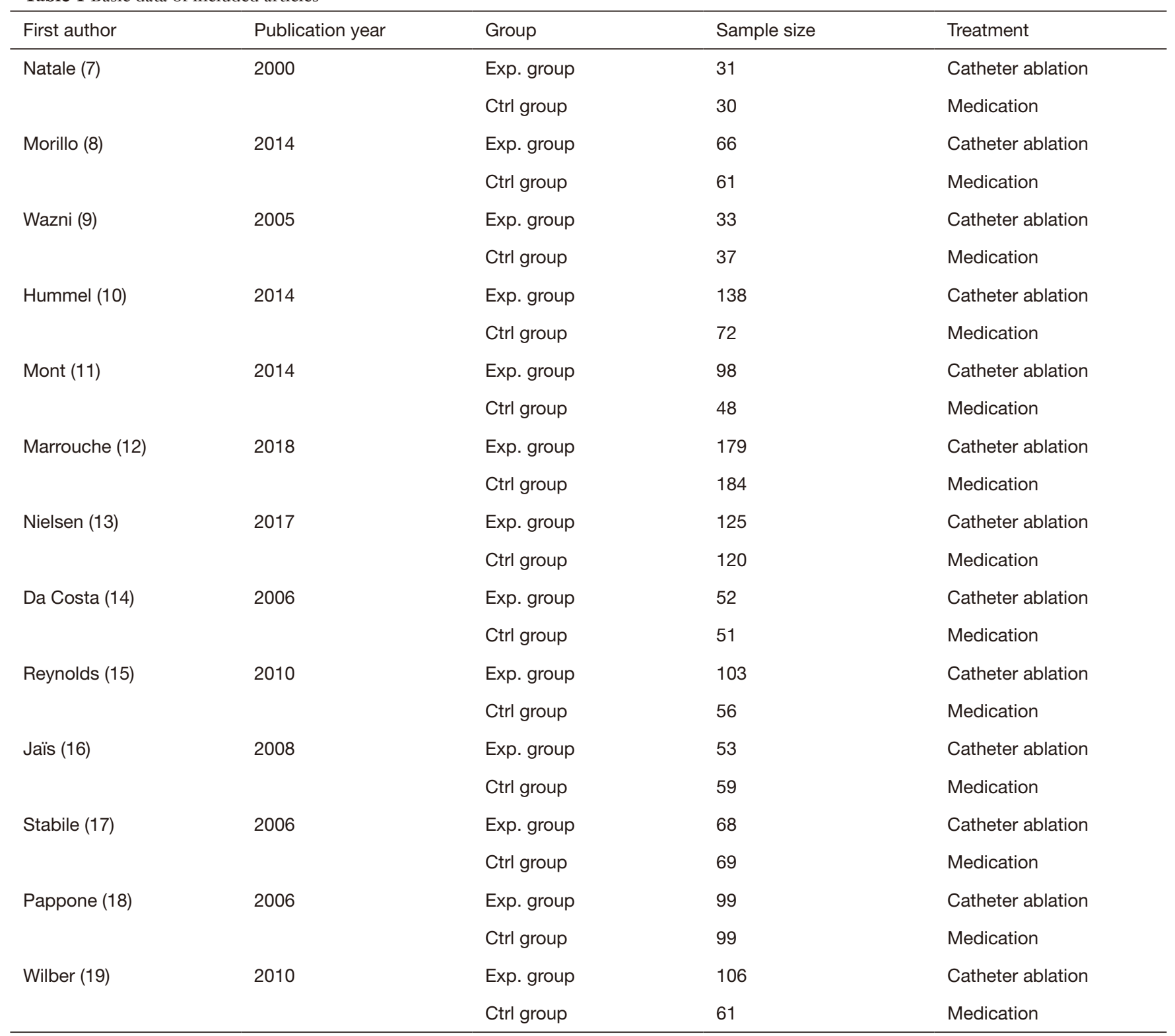

Ctrl group =259). The heterogeneity test results ( $I^{2}=98 \%$, and $\mathrm{P}<0.00001)$ indicated that there was a certain degree of heterogeneity among the studies. The analysis results of the REM in Figure 6 show that the combined effect of this meta-analysis was $\mathrm{MD}=-2.84 ; 95 \% \mathrm{CI},-3.24$ to -2.45 ; $\mathrm{Z}=14.16$; and $\mathrm{P}<0.00001$ ). What's more, the diamond in the forest diagram was on the left side of the vertical line, suggesting that the patients of the Exp. group had less body weakness than those in the Ctrl group.

\section{Quality of life (QOL) score}

The QOL scores of patients were analyzed in 5 articles $(7,11,13-15)$. This included a total of 714 patients (Exp. group =409; Ctrl group =305). The heterogeneity test results $\left(I^{2}=100 \%\right.$, and $\left.\mathrm{P}<0.00001\right)$ indicated that there was a certain degree of heterogeneity among the studies, so a REM was adopted. As shown in Figure 7, the combined effect of this meta-analysis was MD $=14.15$; $95 \%$ CI, 7.24 


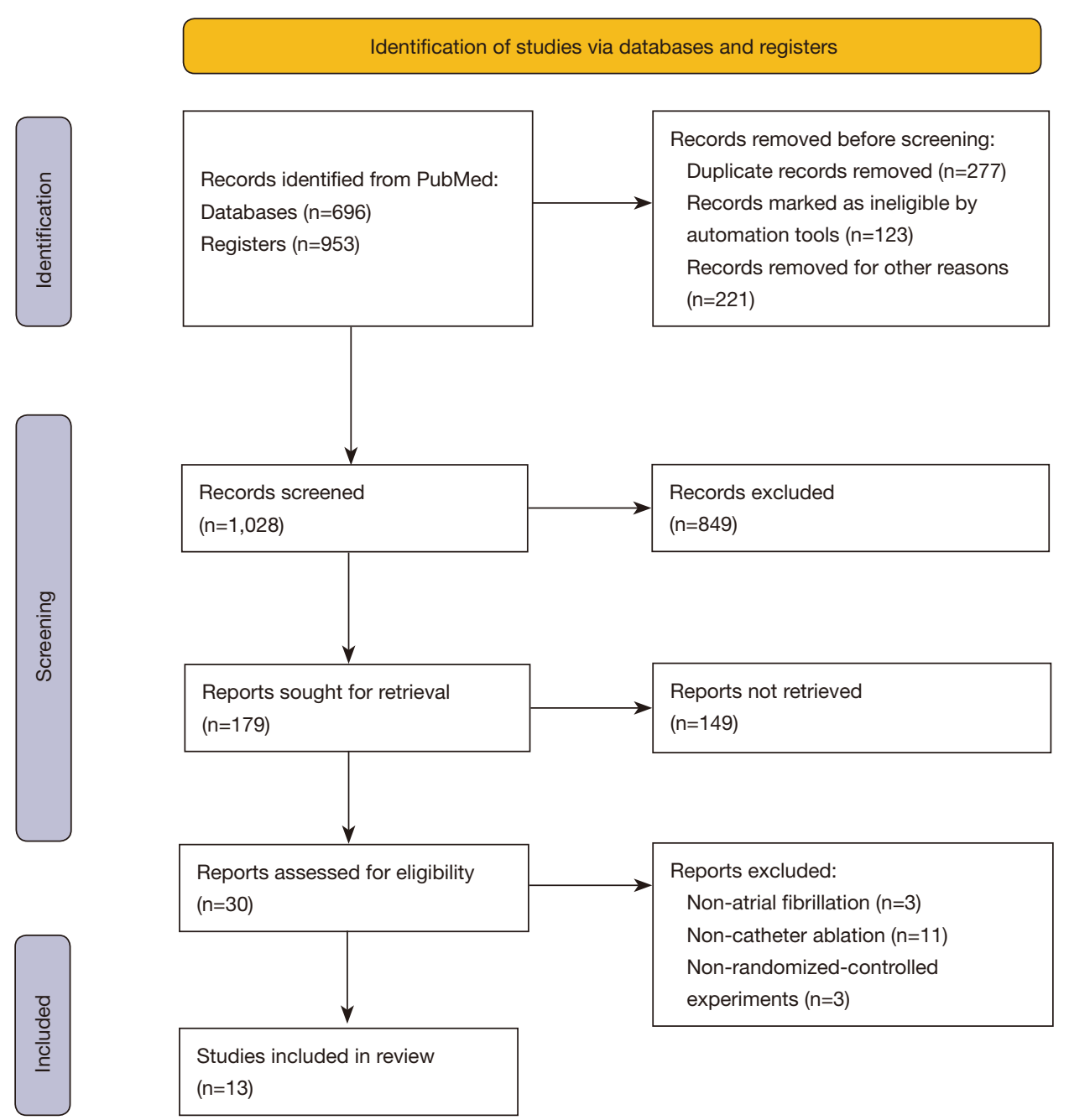

Figure 1 Document retrieval process.

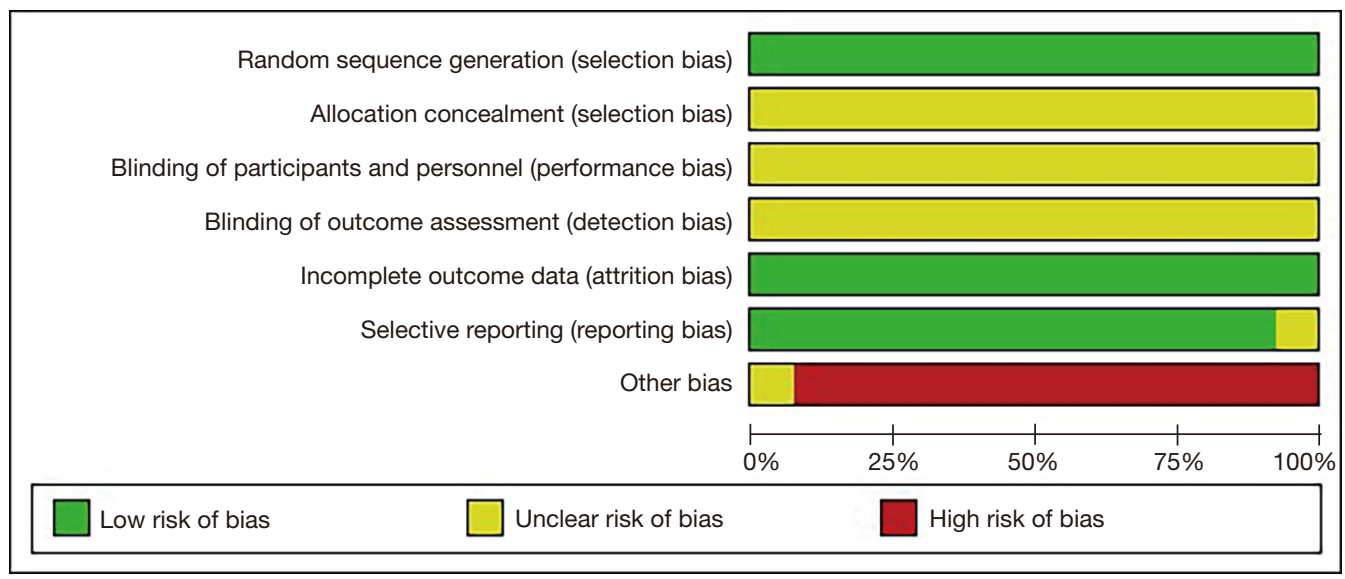

Figure 2 Bar chart for the assessment of the bias risk in the included articles. 


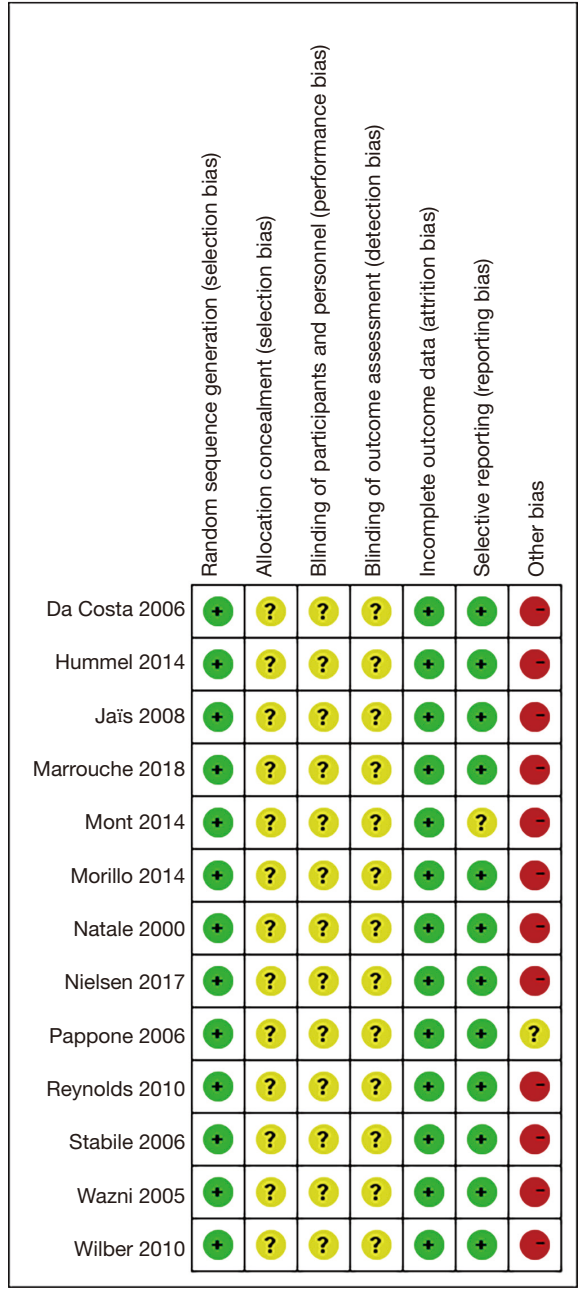

Figure 3 Assessment results of the bias risk in the included articles.
21.05; $\mathrm{Z}=4.01$; and $\mathrm{P}<0.0001)$. In the forest diagram, the diamond was located on the right side of the vertical line, indicating that the QOL score of the Exp. group was higher than that of the Ctrl group.

\section{Pain}

The pain of patients was analyzed in 3 articles $(9,15,17)$. This included 366 patients (Exp. group =204; Ctrl group $=162)$. The heterogeneity test results $\left(\mathrm{I}^{2}=99 \%\right.$, and $\mathrm{P}<0.00001)$ indicated that there was a certain degree of heterogeneity among the articles, so a REM was applied. The analysis results are shown in Figure 8 and illustrate that the combined effect of this meta-analysis was $M D=-2.50$; $95 \%$ CI, -3.11 to $-1.89 ; Z=8.04$; and $\mathrm{P}<0.00001$. The diamond in the forest diagram was on the left side of the vertical line, indicating that the pain level of the Exp. group patients was lower than that of the Ctrl group patients.

\section{Reoccurrence of symptomatic AF}

The reoccurrence of symptomatic AF was analyzed in 3 articles $(9,11,17)$. This included 353 patients (Exp. group =199; Ctrl group =154). The heterogeneity test results $\left(\mathrm{I}^{2}=67 \%, \mathrm{P}=0.05\right)$ suggested that heterogeneity existed among the articles, so an analysis was performed using REM, the results of which are given in Figure 9. It shows that the combined effect of this meta-analysis was $\mathrm{OR}$ $=0.27 ; 95 \% \mathrm{CI}, 0.11-0.67 ; \mathrm{Z}=2.82 ; \mathrm{P}=0.005$. In the forest diagram, the diamond was located on the left side of the

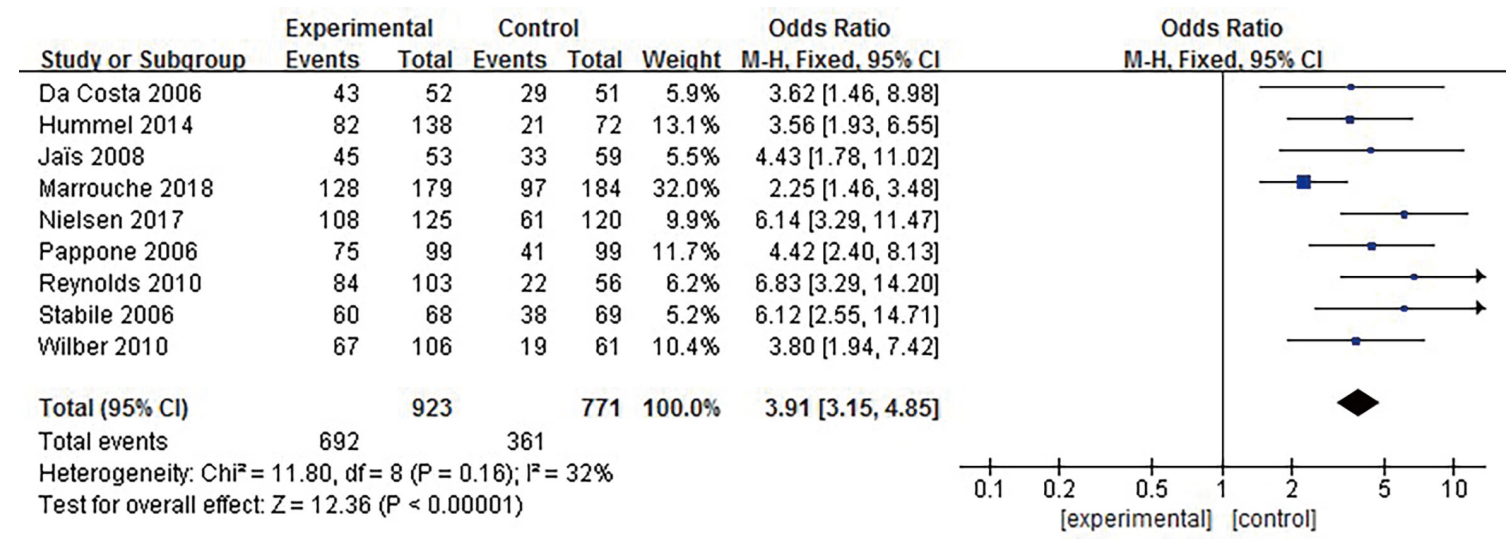

Figure 4 Effect of clinical CA treatment. CA, catheter ablation. 


\begin{tabular}{|c|c|c|c|c|c|c|c|c|c|c|c|}
\hline \multirow[b]{2}{*}{ Study or Subqroup } & \multicolumn{3}{|c|}{ Experimental } & \multicolumn{3}{|c|}{ Control } & \multicolumn{2}{|r|}{ Mean Difference } & \multirow{2}{*}{\multicolumn{2}{|c|}{$\begin{array}{c}\text { Mean Difference } \\
\text { IV, Random, } 95 \% \mathrm{Cl}\end{array}$}} & \\
\hline & Mean & SD & Total & Mean & SD & Total & Weight & IV, Random, $95 \% \mathrm{Cl}$ & & & \\
\hline Da Costa 2006 & 3.7 & 0.1 & 52 & 2.2 & 0.7 & 51 & $24.7 \%$ & $1.50[1.31,1.69]$ & & & - \\
\hline Natale 2000 & 3.6 & 0.6 & 31 & 2.3 & 0.3 & 30 & $24.1 \%$ & $1.30[1.06,1.54]$ & & & \\
\hline Reynolds 2010 & 4.4 & 0.5 & 103 & 2.5 & 0.3 & 56 & $25.6 \%$ & $1.90[1.78,2.02]$ & & & -를- \\
\hline Wazni 2005 & 9.3 & 0.3 & 33 & 8.2 & 0.2 & 37 & $25.6 \%$ & $1.10[0.98,1.22]$ & & & - \\
\hline Total $(95 \% \mathrm{Cl})$ & & & 219 & & & 174 & $100.0 \%$ & $1.45[1.03,1.87]$ & & & \\
\hline $\begin{array}{l}\text { Heterogeneity: Tauª } \\
\text { Test for overall effect }\end{array}$ & $\begin{array}{l}0.17 ; \mathrm{Cl} \\
\mathrm{Z}=6.82\end{array}$ & $\begin{array}{l}2=83 \\
P<0\end{array}$ & $\begin{array}{l}.85, \mathrm{df} \\
.00001)\end{array}$ & $=3(\mathrm{P}$ & 0.00 & $0001) ; I^{\prime}$ & $=96 \%$ & & $\begin{array}{c}-1 \\
\text { [experimental] }\end{array}$ & [control] & $\frac{1}{2}$ \\
\hline
\end{tabular}

Figure 5 Daily life function.

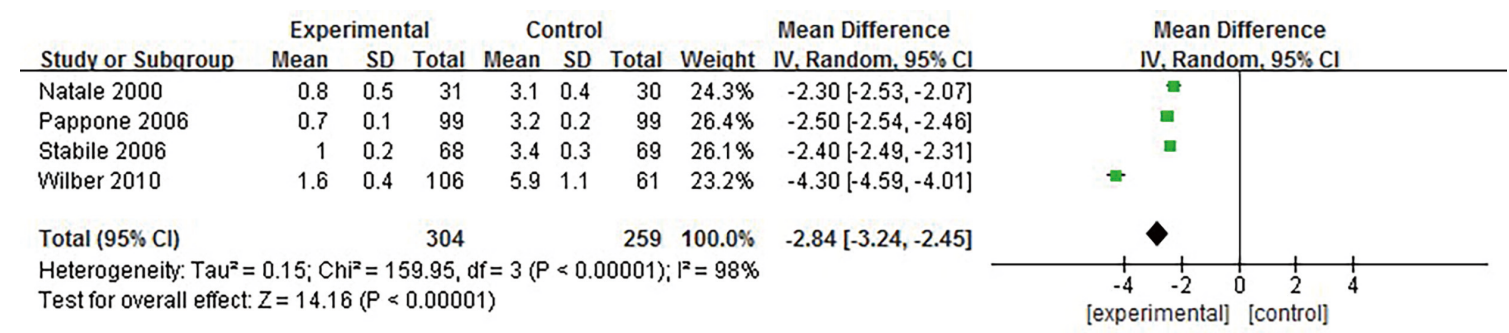

Figure 6 Body weakness.

\begin{tabular}{|c|c|c|c|c|c|c|c|c|c|c|c|}
\hline Study or Subaroup & \multicolumn{3}{|c|}{ Experimental } & \multicolumn{3}{|c|}{ Control } & \multicolumn{2}{|r|}{ Mean Difference } & \multicolumn{2}{|c|}{$\begin{array}{l}\text { Mean Difference } \\
\text { IV, Random, } 95 \% \mathrm{Cl}\end{array}$} & \\
\hline Da Costa 2006 & 55 & 0.6 & 52 & 38 & 0.6 & 51 & $20.1 \%$ & $17.00[16.77,17.23]$ & & घ & \\
\hline Mont 2014 & 56.4 & 0.4 & 98 & 53.2 & 0.2 & 48 & $20.1 \%$ & $3.20[3.10,3.30]$ & & $\square$ & \\
\hline Natale 2000 & $5 ?$ & 6 & 31 & 31 & 5 & 30 & $19.5 \%$ & $26.00[23.23,28.77]$ & & & $\rightarrow$ \\
\hline Nielsen 2017 & 57 & 1 & 125 & 45 & 3 & 120 & $20.1 \%$ & $12.00[11.44,12.56]$ & & 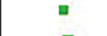 & \\
\hline Reynolds 2010 & 52.3 & 0.6 & 103 & 39.4 & 0.7 & 56 & $20.1 \%$ & $12.90[12.68,13.12]$ & & $=$ & \\
\hline Total $(95 \% \mathrm{Cl})$ & & & 409 & & & 305 & $100.0 \%$ & $14.15[7.24,21.05]$ & & & \\
\hline $\begin{array}{l}\text { Heterogeneity: Tau } \\
\text { Test for overall effec }\end{array}$ & $\begin{array}{l}61.70 ; 0 \\
z=4.01\end{array}$ & $\begin{array}{l}i^{2}=1 \\
P<0\end{array}$ & $\begin{array}{l}6201.1 \\
.0001)\end{array}$ & 4, $d f=$ & $4(P<$ & $=0.000$ & $101) ; I^{2}=1$ & $00 \%$ & $\begin{array}{ccc}-20 & -10 & 0 \\
\text { [experimental] }\end{array}$ & $\int_{[\text {control] }}^{10} 2$ & \\
\hline
\end{tabular}

Figure 7 QOL score. QOL, quality of life.

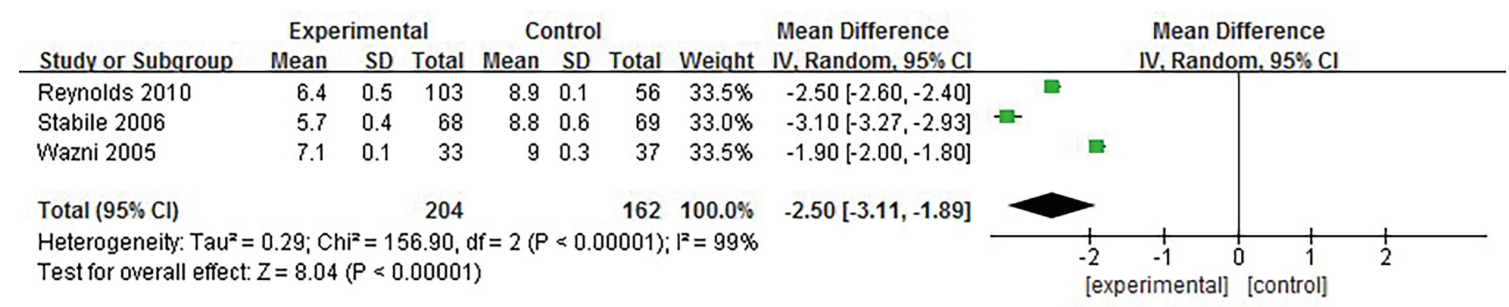

Figure 8 Pain.

vertical line, indicating that the Exp. group showed lower reoccurrence of symptomatic AF than the Ctrl group.

\section{Rebospitalization}

The rehospitalization of patients was analyzed in 5 articles
(9-11,16,18). This included 736 patients (Exp. group $=421$; $\mathrm{Ctrl}$ group $=315$. The heterogeneity test results $\left(\mathrm{I}^{2}=3 \%\right.$, and $\mathrm{P}=0.39$ ) suggested that the heterogeneity among the articles was small. The FEM analysis results are shown in Figure 10. The combined effect of this meta-analysis was $\mathrm{OR}=0.15$; 95\% CI, 0.07-0.31; $\mathrm{Z}=5.11$; and $\mathrm{P}<0.00001)$. The diamond 


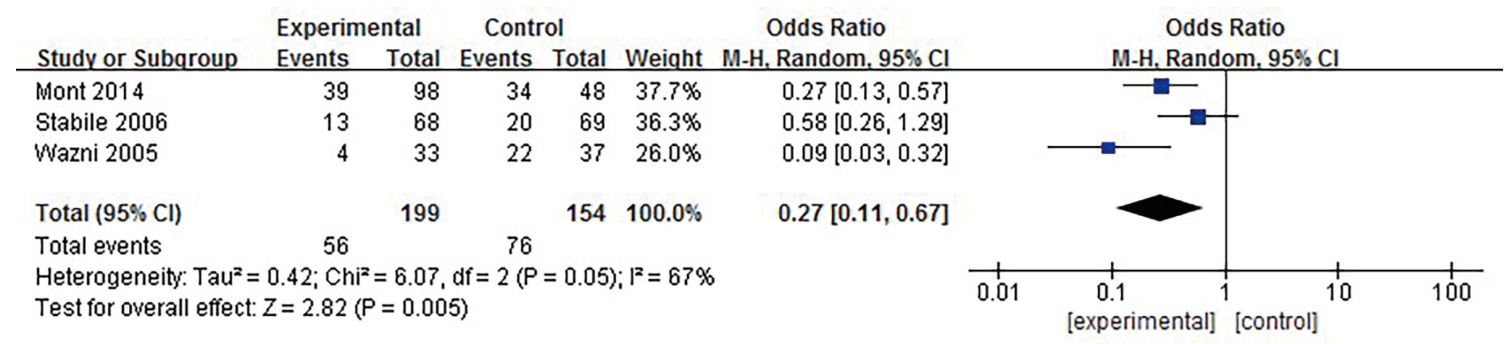

Figure 9 Reoccurrence of symptomatic AF. AF, atrial fibrillation.

\begin{tabular}{|c|c|c|c|c|c|c|c|c|c|c|}
\hline Study or Subgroup & \multicolumn{2}{|c|}{ Experimental } & \multicolumn{2}{|c|}{ Control } & Weight & $\begin{array}{l}\text { Odds Ratio } \\
\text { M-H. Fixed, } 95 \% \mathrm{Cl}\end{array}$ & \multicolumn{3}{|c|}{$\begin{array}{c}\text { Odds Ratio } \\
\text { M-H, Fixed, } 95 \% \mathrm{Cl}\end{array}$} & \\
\hline Hummel 2014 & 1 & 138 & 6 & 72 & $16.9 \%$ & $0.08[0.01,0.68]$ & & & & \\
\hline Jaïs 2008 & 3 & 53 & 7 & 59 & $13.5 \%$ & $0.45[0.11,1.82]$ & & & - & \\
\hline Mont 2014 & 2 & 98 & 3 & 48 & $8.5 \%$ & $0.31[0.05,1.94]$ & & & - & \\
\hline Pappone 2006 & 1 & 99 & 12 & 99 & $25.7 \%$ & $0.07[0.01,0.58]$ & & & & \\
\hline Wazni 2005 & 3 & 33 & 19 & 37 & $35.3 \%$ & $0.09[0.02,0.37]$ & & & & \\
\hline Total $(95 \% \mathrm{Cl})$ & & 421 & & 315 & $100.0 \%$ & $0.15[0.07,0.31]$ & & & & \\
\hline Total events & 10 & & 47 & & & & & & & \\
\hline $\begin{array}{l}\text { Heterogeneity: Chi } \\
\text { Test for overall effec }\end{array}$ & $\begin{array}{l}4.12, d f= \\
Z=5.11(f\end{array}$ & $\begin{array}{l}(P=0 . \\
<0.00\end{array}$ & $\begin{array}{l}\text { 39); }\left.\right|^{2}=3 \\
001)\end{array}$ & & & & 0.001 & $\begin{array}{c}0.1 \\
\text { [experimental] }\end{array}$ & $\begin{array}{l}10 \\
\text { [control] }\end{array}$ & 1000 \\
\hline
\end{tabular}

Figure 10 Rehospitalization of patients.

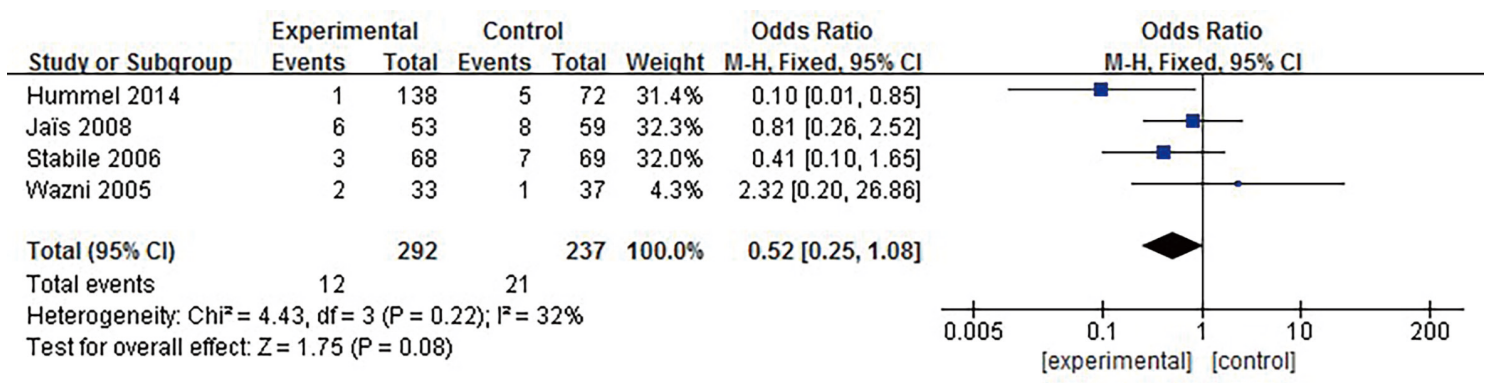

Figure 11 Bleeding.

was found on the left of the vertical line in the forest diagram, suggesting that the rehospitalization of patients in the Exp. group was much lower than that of the patients in the Ctrl group.

\section{Bleeding}

Patient bleeding was analyzed in 4 articles $(9,10,16,17)$. This included 529 patients (Exp. group =292; Ctrl group =237). The heterogeneity test results $\left(\mathrm{I}^{2}=32 \%\right.$, and $\left.\mathrm{P}=0.22\right)$ indicated that the heterogeneity among the articles was small, so a FEM was used for analysis, the results of which are shown in Figure 11. The combined effect of this meta- analysis was $\mathrm{OR}=0.52 ; 95 \% \mathrm{CI}, 0.25-1.08 ; \mathrm{Z}=1.75 ; \mathrm{P}=0.08$. As the diamond was found on the left side of the vertical line in the forest diagram, we determined that the Exp. group showed less incidences of bleeding.

\section{Otber arrbythmia}

Other arrythmia of patients were analyzed in 6 articles (7,911,13,18). This included 930 patients (Exp. group $=524$; Ctrl group =406). The heterogeneity test results $\left(\mathrm{I}^{2}=0 \%\right.$, and $\mathrm{P}=0.93$ ) indicated that heterogeneity was visible among the articles, and so a FEM was used, the results of which can be seen in Figure 12. The combined effect of this 


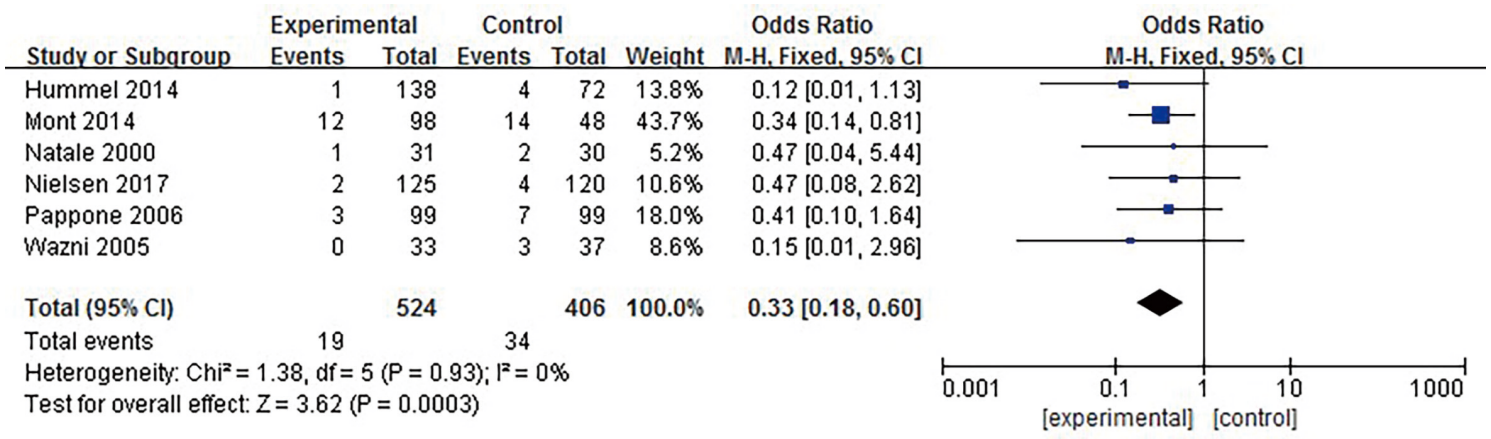

Figure 12 Other arrhythmia.

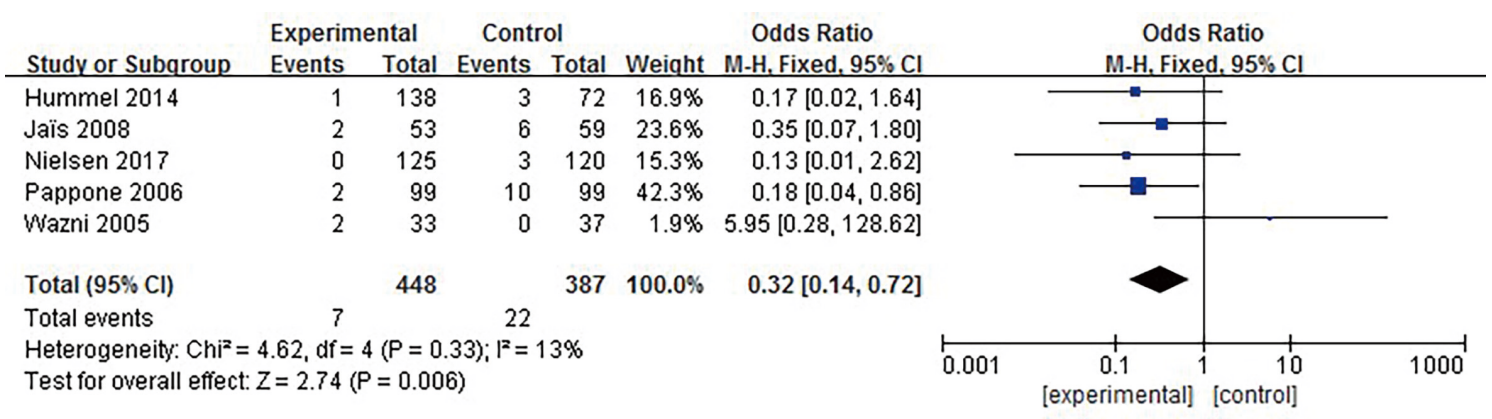

Figure 13 PVS. PVS, pulmonary vein stenosis.

meta-analysis was $\mathrm{OR}=0.33 ; 95 \% \mathrm{CI}, 0.18-0.60 ; \mathrm{Z}=3.62$; $\mathrm{P}=0.0003)$. In addition, the diamond in the forest diagram was located on the left side of the vertical line, suggesting that the Exp. group showed lower incidences of other arrhythmia.

\section{Pulmonary vein stenosis (PVS)}

We analyzed 5 articles $(9,10,13,16,18)$ on PVS. This included 835 patients (Exp. group $=448$; Ctrl group $=387$ ). The heterogeneity test results $\left(\mathrm{I}^{2}=13 \%\right.$, and $\left.\mathrm{P}=0.33\right)$ suggested that the heterogeneity among different articles was not obvious, and so a FEM analysis was conducted. As illustrated in Figure 13, the combined effect of our meta-analysis was $\mathrm{OR}=0.32 ; 95 \% \mathrm{CI}, 0.14-0.72 ; \mathrm{Z}=2.74$; $\mathrm{P}=0.006)$. The forest diagram showed that the diamond was located on the left side of the vertical line, indicating that PVS was lower in the Exp. group.

\section{Analysis of publication bias}

With the help of Review Manager 5.3 software, publication bias was analyzed in terms of the effect of CA in the treatment of AF patients. As shown in Figure 14, the clinical efficacy, daily life function, body weakness, QOL score, occurrence of symptomatic AF, rehospitalization, bleeding, other arrhythmia, and PVS were all basically distributed within the CI, resulting in a low bias. However, in regard to the pain level analysis, some of the scattered points in the funnel chart were out of the CI, suggesting a relatively scattered distribution. This indicates that among the articles there was a certain publication bias in regard to pain level.

\section{Discussion}

Clinically speaking, AF is one of the most common, rapid arrhythmia, and carries severe associated risks, including cerebral embolism (20-22). Other researchers have observed that the peculiar smell and excitement of the pulmonary veins can initiate paroxysmal $\mathrm{AF}$, making it possible for radiofrequency $\mathrm{CA}$ to be used for $\mathrm{AF}$ (23). The pathological mechanism of AF is mainly caused by the constant impulse of one or more odor excitatory foci, so its treatment can be achieved by eliminating or isolating the site of such activity 
A

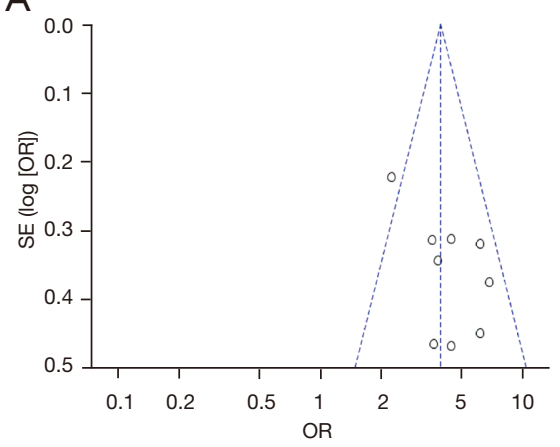

D

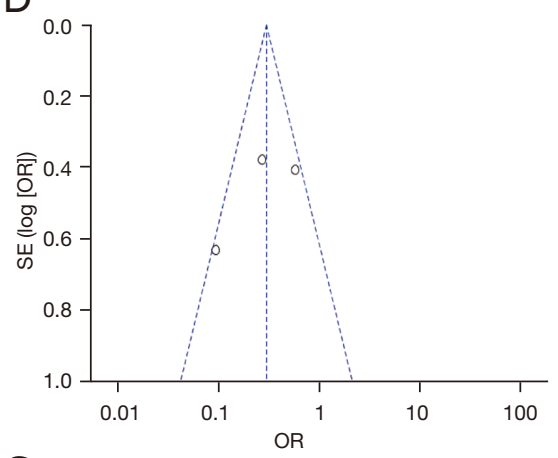

G
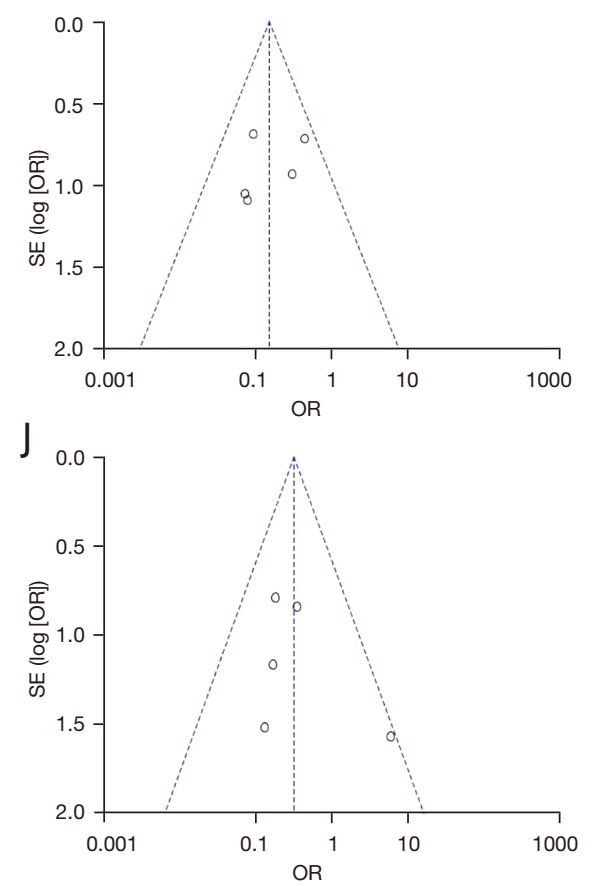

B

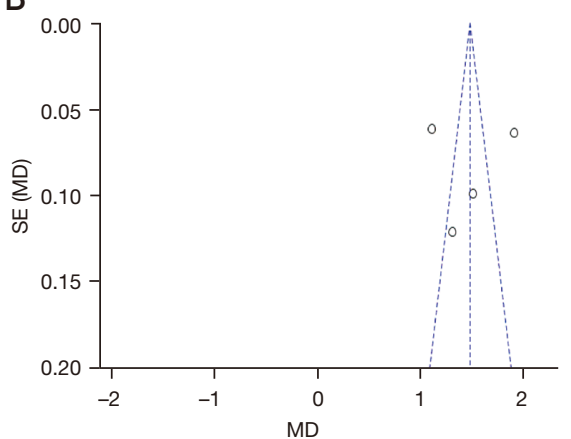

E

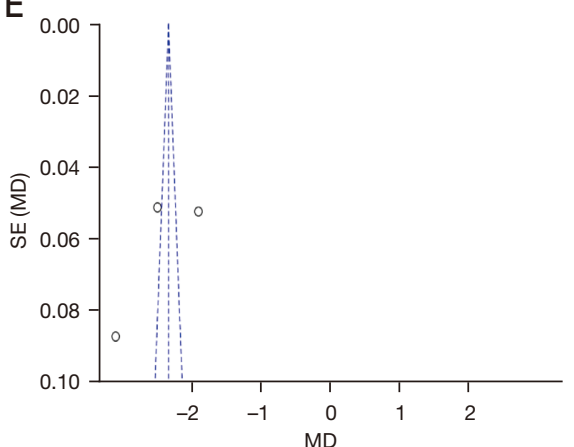

$\mathrm{H}$

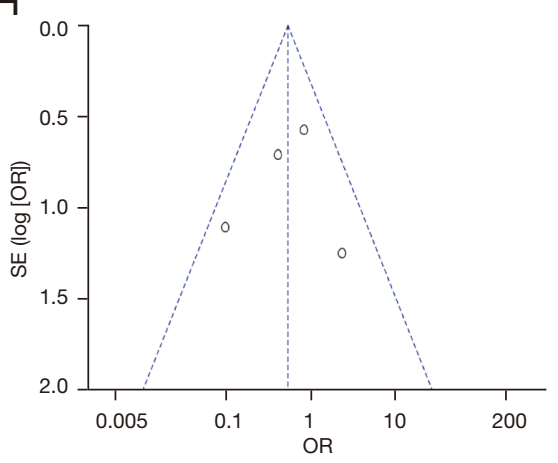

C

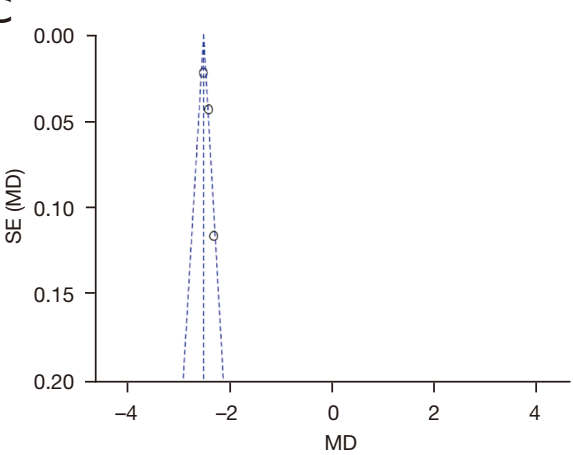

$\mathrm{F}$

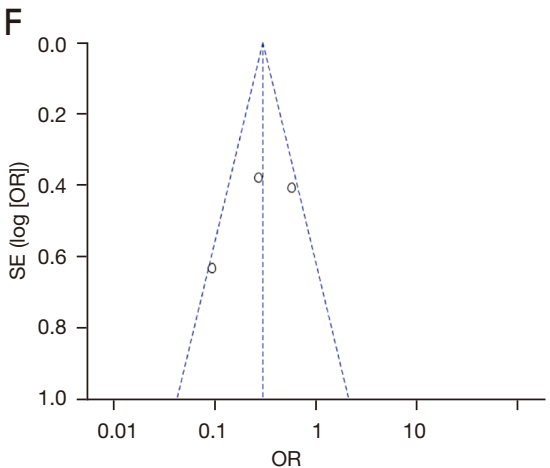

I

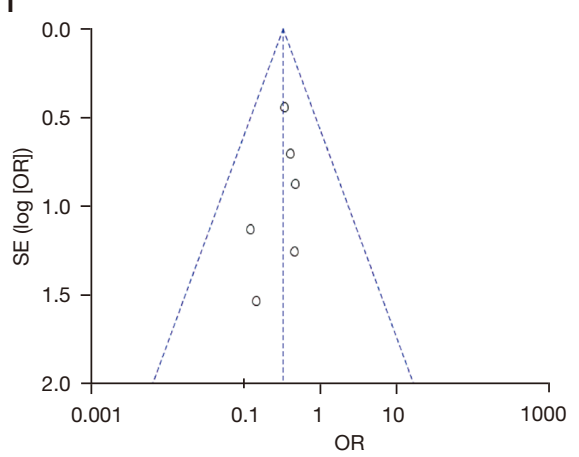

Figure 14 Funnel chart of various outcome evaluation indicators. (A) Effect of clinical CA treatment, (B) daily life function, (C) body weakness, (D) QOL score, (E) pain, (F) reoccurrence of symptomatic AF, (G) rehospitalization, (H) bleeding, (I) other arrhythmia, and (J) PVS. CA, catheter ablation; QOL, quality of life; AF, atrial fibrillation; PVS, pulmonary vein stenosis. 
(24-26). With continuing improvements in CA technology, more and more patients have chosen CA treatment in recent years, and patients who have undergone drug treatment with unsatisfactory results, also often opt for CA treatment (27). As the clinical application of this treatment method has significantly improved, surgeons can now better ensure the safety of patients and control postoperative pain responses. In addition, it is also now considered to be a safe and effective surgical method for clinical treatment (28). Catheter ablation has some unique advantages: the cryo catheter is firmly attached to the tissue during the ablation process, and it is not easy to shift, which can further reduce unnecessary time consumption and enhance safety. Compared with radio frequency energy, cryoablation does not damage tissue cells. Theoretically, it can reduce the damage of the endocardial surface, and at the same time, make the ablation more uniform and thorough, which is beneficial to improve the long-term success rate, decrease recurrence, and reduce complications such as mural thrombosis. However, this method has low power and a high incidence of pulmonary vein stenosis, which can be as high as $42 \%$.

In this study, 13 articles were evaluated and metaanalyzed to systematically assess the efficacy of CA in the treatment of patients with AF (29). The results of this study showed that the Exp. group patients who underwent CA had a more positive treatment experience and saw an improvement in their daily life function. The radiofrequency $\mathrm{CA}$ arrythmia treatment method used in this study is currently used by the Chinese Cardiac Intervention Center (30). It integrates various medical methods such as radiofrequency ablation, digital subtraction angiography (DSA) interventional technology, and vascular imaging technology. In addition, it has excellent curative effects on arrhythmia caused by various types of physiological and electrical abnormalities. When compared with transfemoral artery puncture and interventional radiofrequency CA, the CA of a radial artery puncture reduces the pain of patients to a certain extent. There is no need for in-bed immobilization, or for sandbag pressurization after surgery, which reduces the chance of infection and thrombosis, an obvious advantage (31). In this study, it was found that after treatment, incidences of adverse reactions in the Exp. group, such as rehospitalization, arrhythmia, PVS, and reoccurrence of $\mathrm{AF}$, were lower than those in the Ctrl group. This reflects the significant advantages of CA.

\section{Conclusions}

Our meta-analysis of the efficacy of CA in the treatment of patients with AF included 13 articles and involved 2,098 patients with AF. The results showed that when compared with drug therapy, CA can greatly reduce incidences of adverse reactions in patients, thereby improving their clinical outcomes. This suggests CA is significantly superior to traditional drug treatments. However, there were some limitations in this study. This mainly includes the large publication bias found in some articles. In addition, some analysis indicators contained only a small number of samples due to differences in the research directions of the authors, so the meta-analysis results may not be accurate enough. Therefore, in future studies, it will be necessary to select larger samples of high-quality CA treatments to verify its effect on $\mathrm{AF}$.

\section{Acknowledgments}

Funding: None.

\section{Footnote}

Reporting Checklist: The authors have completed the PRISMA reporting checklist. Available at https://dx.doi. org/10.21037/apm-21-2313

Conflicts of Interest: All authors have completed the ICMJE uniform disclosure form (available at https://dx.doi. org/10.21037/apm-21-2313). The authors have no conflicts of interest to declare.

Ethical Statement: The authors are accountable for all aspects of the work in ensuring that questions related to the accuracy or integrity of any part of the work are appropriately investigated and resolved.

Open Access Statement: This is an Open Access article distributed in accordance with the Creative Commons Attribution-NonCommercial-NoDerivs 4.0 International License (CC BY-NC-ND 4.0), which permits the noncommercial replication and distribution of the article with the strict proviso that no changes or edits are made and the original work is properly cited (including links to both the formal publication through the relevant DOI and the license). 
See: https://creativecommons.org/licenses/by-nc-nd/4.0/.

\section{References}

1. Achkasov E, Bondarev S, Smirnov V, et al. Atrial Fibrillation in Athletes-Features of Development, Current Approaches to the Treatment, and Prevention of Complications. Int J Environ Res Public Health 2019;16:4890.

2. Kounis NG, Koniari I, Tzanis G, et al. Anaphylaxisinduced atrial fibrillation and anesthesia: Pathophysiologic and therapeutic considerations. Ann Card Anaesth 2020;23:1-6.

3. Kanmanthareddy A, Emert MP, Pimentel RC, et al. Lone atrial fibrillation: electrophysiology, risk factors, catheter ablation and other non-pharmacologic treatments. Curr Pharm Des 2015;21:580-90.

4. Nattel S, Dobrev D. Controversies About Atrial Fibrillation Mechanisms: Aiming for Order in Chaos and Whether it Matters. Circ Res 2017;120:1396-8.

5. Calkins H. Important Differences Exist Between Atrial Fibrillation and Atrial Flutter in Atrial Remodeling. J Am Coll Cardiol 2020;76:389-90.

6. Goudis CA, Vasileiadis IE, Liu T. Epicardial adipose tissue and atrial fibrillation: pathophysiological mechanisms, clinical implications, and potential therapies. Curr Med Res Opin 2018;34:1933-43.

7. Natale A, Newby KH, Pisanó E, et al. Prospective randomized comparison of antiarrhythmic therapy versus first-line radiofrequency ablation in patients with atrial flutter. J Am Coll Cardiol 2000;35:1898-904.

8. Morillo CA, Verma A, Connolly SJ, et al. Radiofrequency ablation vs antiarrhythmic drugs as first-line treatment of paroxysmal atrial fibrillation (RAAFT-2): a randomized trial. JAMA 2014;311:692-700.

9. Wazni OM, Marrouche NF, Martin DO, et al. Radiofrequency ablation vs antiarrhythmic drugs as first-line treatment of symptomatic atrial fibrillation: a randomized trial. JAMA 2005;293:2634-40.

10. Hummel J, Michaud G, Hoyt R, et al. Phased RF ablation in persistent atrial fibrillation. Heart Rhythm 2014;11:202-9.

11. Mont L, Bisbal F, Hernández-Madrid A, et al. Catheter ablation vs. antiarrhythmic drug treatment of persistent atrial fibrillation: a multicentre, randomized, controlled trial (SARA study). Eur Heart J 2014;35:501-7.

12. Marrouche NF, Brachmann J, Andresen D, et al. Catheter Ablation for Atrial Fibrillation with Heart Failure. N Engl
J Med 2018;378:417-27.

13. Nielsen JC, Johannessen A, Raatikainen P, et al. Longterm efficacy of catheter ablation as first-line therapy for paroxysmal atrial fibrillation: 5-year outcome in a randomised clinical trial. Heart 2017;103:368-76.

14. Da Costa A, Thévenin J, Roche F, et al. Results from the Loire-Ardèche-Drôme-Isère-Puy-de-Dôme (LADIP) trial on atrial flutter, a multicentric prospective randomized study comparing amiodarone and radiofrequency ablation after the first episode of symptomatic atrial flutter. Circulation 2006;114:1676-81.

15. Reynolds MR, Walczak J, White SA, et al. Improvements in symptoms and quality of life in patients with paroxysmal atrial fibrillation treated with radiofrequency catheter ablation versus antiarrhythmic drugs. Circ Cardiovasc Qual Outcomes 2010;3:615-23.

16. Jaïs P, Cauchemez B, Macle L, et al. Catheter ablation versus antiarrhythmic drugs for atrial fibrillation: the A4 study. Circulation 2008;118:2498-505.

17. Stabile G, Bertaglia E, Senatore G, et al. Catheter ablation treatment in patients with drug-refractory atrial fibrillation: a prospective, multi-centre, randomized, controlled study (Catheter Ablation For The Cure Of Atrial Fibrillation Study). Eur Heart J 2006;27:216-21.

18. Pappone C, Augello G, Sala S, et al. A randomized trial of circumferential pulmonary vein ablation versus antiarrhythmic drug therapy in paroxysmal atrial fibrillation: the APAF Study. J Am Coll Cardiol 2006;48:2340-7.

19. Wilber DJ, Pappone C, Neuzil P, et al. Comparison of antiarrhythmic drug therapy and radiofrequency catheter ablation in patients with paroxysmal atrial fibrillation: a randomized controlled trial. JAMA 2010;303:333-40.

20. John RM, Mitra R. Atrial conduction velocity and risk of recurrent atrial fibrillation after ablation: Time to blank the blanking period? J Cardiovasc Electrophysiol 2020;31:1950-2.

21. Nishida K, Nattel S. Atrial fibrillation compendium: historical context and detailed translational perspective on an important clinical problem. Circ Res 2014;114:1447-52.

22. Ehrlich MP, Laufer G, Coti I, et al. Noninvasive mapping before surgical ablation for persistent, long-standing atrial fibrillation. J Thorac Cardiovasc Surg 2019;157:248-56.

23. Kabra R, Singh JP. Catheter ablation targeting complex fractionated atrial electrograms for the control of atrial fibrillation. Curr Opin Cardiol 2012;27:49-54.

24. Grönefeld GC, Hohnloser SH. Heart failure complicated 
by atrial fibrillation: mechanistic, prognostic, and therapeutic implications. J Cardiovasc Pharmacol Ther 2003;8:107-13.

25. San Antonio R, Guasch E, Tolosana JM, et al. Determining the best approach to reduce the impact of exercise-induced atrial fibrillation: prevention, screening, or symptom-based treatment? Expert Rev Cardiovasc Ther 2019;17:19-29.

26. Bradley DJ, Shen WK. Overview of management of atrial fibrillation in symptomatic elderly patients: pharmacologic therapy versus AV node ablation. Clin Pharmacol Ther 2007;81:284-7.

27. Brugts JJ, Akin S, Helming AM, et al. The predictive value of cardiac biomarkers in prognosis and risk stratification of patients with atrial fibrillation. Curr Opin Cardiol 2011;26:449-56.

28. Koh LY, Hwang NC. Serum Electrolyte Concentrations and Their Association With Postoperative Atrial

Cite this article as: Wang $\mathrm{P}, \mathrm{He}$ W, Li C, Xiang T, Yang Q, Chen Q. A systematic review and meta-analysis of catheter ablation for atrial fibrillation. Ann Palliat Med 2021;10(10):1054210555. doi: 10.21037/apm-21-2313
Fibrillation: A Long-Standing Myth or Reality? J

Cardiothorac Vasc Anesth 2020;34:1160-1.

29. Kirchhof P, Lip GY, Van Gelder IC, et al. Comprehensive risk reduction in patients with atrial fibrillation: Emerging diagnostic and therapeutic options. Executive summary of the report from the $3 \mathrm{rd}$ AFNET/EHRA consensus conference. Thromb Haemost 2011;106:1012-9.

30. Wissner E, Deiss S, Kuck KH. Balloon-based pulmonary vein isolation for the treatment of paroxysmal atrial fibrillation (cryoballoon and laserballoon). Future Cardiol 2015;11:663-71.

31. Dobrev D, Nattel S. New insights into the molecular basis of atrial fibrillation: mechanistic and therapeutic implications. Cardiovasc Res 2011;89:689-91.

(English Language Editor: J. Goetz) 